\title{
BMJ Open Mindfulness-based programmes to reduce stress and enhance well-being at work: a realist review
}

\author{
Katrin Micklitz (D) , ${ }^{1}$ Geoff Wong (D) , ${ }^{2}$ Jeremy Howick (D) ${ }^{3}$
}

To cite: Micklitz K, Wong G, Howick J. Mindfulness-based programmes to reduce stress and enhance well-being at work: a realist review. BMJ Open 2021;11:e043525. doi:10.1136/ bmjopen-2020-043525

- Prepublication history and additional materials for this paper is available online. To view these files, please visit the journal online (http://dx.doi. org/10.1136/bmjopen-2020043525).

Received 06 August 2020 Revised 10 February 2021 Accepted 18 February 2021

Check for updates

(c) Author(s) (or their employer(s)) 2021. Re-use permitted under CC BY-NC. No commercial re-use. See rights and permissions. Published by BMJ.

${ }^{1}$ Evidence-Based Healthcare, Department of Continuing Education, University of Oxford, Oxford, UK

${ }^{2}$ Nuffield Department of Primary Care Health Sciences, University of Oxford, Oxford, UK

${ }^{3}$ Faculty of Philosophy, University of Oxford, Oxford, UK

Correspondence to

Katrin Micklitz;

katrin.micklitz@kellogg.ox.ac.uk

\section{ABSTRACT}

Objectives To understand how and why workplace mindfulness-based programmes (MBPs) work or do not work.

Design A realist review.

Eligibility criteria for selection We considered any studies (experimental quasi-experimental, observational, qualitative and mixed-methods studies) of workplace MBPs as long as they provided data to explain our programme theories. All MBP formats and delivery modes were included.

Analysis Consistent with realist review methodology, we systematically screened and analysed data to explain how and why workplace MBPs work or do not work. These explanations were consolidated into a programme theory augmented by theories from organisational literature, such as conservation of resources theory.

Results Findings from 75 primary studies suggest that workplace MBPs enable participants (including healthcare professionals) to deal more skillfully with stressful events and improve their well-being. The mechanisms involved can be grouped around awareness/self-regulation, acceptance/compassion, feeling permitted to take care of self, sense of growth and promise of goal attainment. In order for professionals to invest in an MBP and benefit from it, it is important that they feel safe to engage with self-care at work and share emotional difficulties among peers. It is also important that employees are able to link the programme and its activities to existing goals and practices. Concerns of being non-productive, of not getting work done or of being exposed in front of colleagues can result in strategic use of brief mindfulness exercises, nonadherence or drop-out.

Conclusions Simply offering an MBP to (healthcare) professionals in order to reduce stress and enhance wellbeing does not suffice. A supportive environment must exist in order for the programme's benefits to be reaped. PROSPERO registration number CRD42018086280.

\section{BACKGROUND}

Mental health problems have become one of the leading causes for absenteeism from work and early retirement in all industrialised countries. This has far reaching consequences not only for the individual and for organisations but for economies and societies as a whole. ${ }^{1}$ The total cost of reduced productivity including absenteeism due to

\section{Strengths and limitations of this study}

To our knowledge, this is the first realist review to explain how, why and under what circumstances workplace mindfulness-based programmes may improve employee health and well-being.

- Using a realist review approach has enabled us to provide findings that are transferable across a wide range of healthcare professional groups and settings.

- We looked at a broad range of disparate documents to develop our findings.

- Available data from included documents did not allow us to unpack many of the health-related outcomes.

More primary data specifically focused on aspects of our realist programme theory is needed.

mental health disorders within the European Union has been reported to be $€ 136$ billion per year. ${ }^{2}$ In the UK, between 2009 and 2013, the number of sick days lost to stress, depression and anxiety has increased by $24 \%$ and the number lost to serious mental illness has doubled. ${ }^{3}$ Burn-out seems to be particularly prevalent among healthcare professionals, ${ }^{45}$ with $31.5 \%$ of medical doctors reporting burn-out in a large 2018 study in the UK. ${ }^{4}$

Given these developments, organisations, including in healthcare, increasingly invest in mental health programmes for their employees to reduce stress and burn-out. Evidence suggests that these programmes can be effective, ${ }^{6}$ especially if they are used as preventative strategies and address subthreshold conditions. ${ }^{7}$ Among these preventative workplace health interventions, mindfulness-based programmes (MBPs) have, over the last decade caught the interest not only of leaders and employers around the world but also of policy-makers. ${ }^{89}$ Mindfulness is seen to have widespread effects on human functioning and behaviour with an impact on mental health, well-being, physical health, self-regulation and interpersonal 
behaviour. ${ }^{10}$ Meta-analytical evidence on a wide range of professions and industries suggests that workplace MBPs reduce stress and distress in employees while promoting various aspects of well-being. ${ }^{1-16}$ A series of reviews ${ }^{17-21}$ and meta-analyses ${ }^{22-27}$ found that mindfulness training enhances mental health and psychological functioning in healthcare professionals. Meta-analytical evidence further found increased levels of (self-)compassion in employees after workplace mindfulness training. ${ }^{13} 2528$

However promising, these findings leave us with unresolved issues that limit our ability to apply the evidence. For one, MBPs are multifaceted, generally consisting of numerous potential active ingredients (eg, experiential practices, psychoeducation, social support $)^{29}$ and they vary considerably with regards to their duration and mode of delivery. ${ }^{11}$ At present the current evidence does not indicate what exactly makes these programmes successful. In addition, high attrition rates ${ }^{2326}$ together with evidence of publication bias ${ }^{11} 13142325$ and great heterogeneity in outcomes between studies ${ }^{12} 13240$ indicate that workplace MBPs might work less well than is believed or, more likely, only in certain settings, for certain individuals and under certain circumstances.

Given these limitations of existing evidence on workplace MBPs, it seems rational that in order to be able to develop and implement effective and sustainable programmes that can be applied across groups and settings, including in healthcare, we should not only look at their net effects but investigate how and why they work (or do not work). Such an investigation will generate the knowledge needed to understand better what needs to be done to implement workplace MBPs. The present review was thus structured around the following research questions: (1) What are the outcomes in workplace MBPs? (2) What are the mechanisms causing these outcomes? (3)
Under what conditions (contexts) do these mechanisms become active?

\section{METHODS}

In order to examine our research questions, we took a realist review approach, underpinned by a realist philosophy of science and causality. The purpose of a realist review is explanatory. ${ }^{3132}$ It seeks to explain how and why programmes generate different outcomes in different contexts. MBPs are complex interventions. ${ }^{33}$ They are embedded in organisational structures and cultures and they involve human agency. Much of the existing research on mechanisms in MBPs has focused on neurobiological and cognitive processes involved in the practice of mindfulness (particularly in meditation as one key element of MBPs) ${ }^{34-36}$ Yet, while the outcomes of a workplace MBP may represent changes in cognitive functions, social aspects such as structures, norms, values and beliefs might have an impact on how these changes come about and what they mean. We need theories of how an MBP interacts with the workplace ${ }^{37}$ and how that might affect outcomes. A realist review approach provides the tools and rationale for handling complexity in programmes. It moves beyond looking at the mechanisms of change proposed by an 'official' programme theory of MBPs to see how these mechanisms play out in real life and what other mechanisms might get activated that help explain outcomes patterns. The results are presented in a realist programme theory, expressed in the form of contextmechanism-outcome configurations (CMOCs). For definitions of context, mechanism and outcome see table 1.

Our realist review ran from January 2018 to February 2019. Following the Realist And MEta-narrative Evidence Syntheses: Evolving Standards (RAMESES) quality and

Table 1 Definitions of context, mechanism and outcome (CMO)

Context Context describes the conditions and circumstances that trigger mechanisms. Context can refer to an individual's characteristics and capacities, the properties of a programme, interpersonal relations, institutional rules and norms as well as the wider social, economic and cultural setting. In realist reviews, context cannot be understood independently of a mechanism; it is the specific condition that triggers or modifies a particular mechanism which then generates the outcome of interest.

$\begin{array}{ll}\text { Mechanism } & \text { Mechanisms are the 'agents of action' in a programme. They are not necessarily identical with the } \\ & \text { mechanisms hypothesised in the official programme theory. A central tenet in realism that underpins } \\ \text { realist reviews is that it is not the programme itself or its ingredients that generate outcome but an } \\ \text { individual's reaction to it. A programme offers resources or other opportunities and how these are } \\ \text { taken up depends on a stakeholder's choices (reasoning) and their capacity to put these choices into } \\ \text { practice. A further tenet is that mechanisms are context sensitive, which means, they only get activated } \\ \text { in certain contexts. Based on these assumptions, mechanisms in this review are understood to } \\ \text { describe how the resources or other opportunities provided by a workplace MBP impact an employee's } \\ \text { reasoning and behaviour from which various outcomes will then follow. } \\ \text { The impact or behaviours resulting from the interaction between mechanisms and contexts. Realist } \\ \text { review is not so much interested in the degree to which a programme achieves its effects but rather } \\ \text { seeks to explain outcome patterns (ie, how different outcomes are produced in different contexts.) } \\ \text { Context-mechanism- } \\ \text { In realism, causation is described in form of CMO configurations where particular features of context } \\ \text { outcome configuration } \\ \text { (C) activate spcific mechanisms (M) that generate certain outcomes (O). }\end{array}$


publication standards, ${ }^{38}$ our review progressed iteratively through the following six phases: (1) defining the scope of the review; (2) identifying existing theories; (3) searching for evidence; (4) appraising papers; (5) extracting data and organising findings and (6) analysing and synthesising data to develop a realist programme theory.

\section{Step 1: defining the scope of the review}

To focus the scope of this review, stakeholders (one human relations representative, three MBP instructors, one researcher and one potential participant) were informally consulted. Based on their feedback, we did not focus on any particular professional group or industry, nor were there any geographic restrictions. However, research done in the fields of sports, arts and military was not considered, as contexts in these settings were judged to differ considerably from general workplace settings. The same applies to studies done exclusively with professionals in training (students, trainees, residents). ${ }^{27}$ Since training site was regarded to be potentially important for context, off-site programmes for professionals were included and will be referred to as 'workplace MBPs' as well.

\section{Step 2: identifying existing theories}

The aim of this step was to draft an initial programme theory of how workplace MBPs are supposed to work that would then be modified and refined into a realist programme theory in light of emerging evidence. To develop an initial programme theory, we consulted existing mindfulness frameworks and $\mathrm{KM}$ talked to experts from the field. MBPs are based on a wide range of theories drawing from Buddhist and Western psychology, cognitive science, neuroscience, medicine and education. ${ }^{39}$ A summary of the most common theories that we drew on to develop our initial programme theory of MBPs as mental health and workplace intervention (box 1) may be found in online supplemental file 1 .

\section{Step 3: search for evidence}

Drawing on adaptations from a related systematic review, ${ }^{15}$ our search strategy used the term 'mindfulness' in combination with various search terms for the concept of 'work'. The following databases were searched in January 2018: Embase, MEDLINE, PsycINFO, PubMed, Web of

Box 1 Initial programme theory of workplace mindfulness-based programmes (MBPs)

Through the practice of mindfulness, participants learn to (1) regulate their attention, emotions and behaviour and (2) relate to their experience with acceptance and compassion, which leads to reduced perceptions of stress and to enhanced well-being. These outcomes are brought about by an individual's reasoning and reactions (mechanisms) to the activities/resources provided by the workplace MBP. The activation of the mechanisms will be context dependent, that is, they will only get triggered under certain circumstances. There might be additional or alternative theories that could explain the benefits of workplace MBPs.
Science, Scopus, CINAHL, Business Source Complete and ABI/INFORM Global. We considered all studies and dissertations regardless of methodology or study design. We included documents in English, German, French, Spanish and Portuguese. With respect to MBPs, we included all formats and delivery modes. Our decisions about which programme types to include were guided by Crane $e t a l$ s framework of MBPs. ${ }^{39}$ Citation tracking was used to cross-check whether all relevant studies had been identified. The initial search only covered documents up to 9 September 2018. We ran update searches using the same search strategy in September 2019 and at the end of May 2020. Since no additional concepts could be identified in documents that we found in these update searches we did not include them in our analysis. KM reviewed all citations against title and abstract for inclusion or exclusion. A randomly selected subsample of $10 \%$ was reviewed independently by $\mathrm{GW}$ and $\mathrm{JH}$. Inconsistencies were resolved via discussion. A complete overview of our search strategies and a full list of our inclusion/exclusion criteria can be found in online supplemental file 2 .

\section{Step 4: appraising papers}

In accordance with RAMESES realist synthesis methodology, quality assessment focused on two main criteria: (1) whether the document contributed to theory testing/ refinement (relevance) and (2) whether the methods used to generate the relevant data were credible and trustworthy (rigour) ${ }^{38} \mathrm{KM}$ read the full texts of all included documents and decided whether they contained data relevant to the realist review-that is, could inform some aspect of the programme theory. Assessment of rigour was not performed on the basis of predefined quality standards or with regard to the entire study but instead was made only for specific sections of relevant data contained within included studies. ${ }^{40}$ In one case,${ }^{41}$ for instance, the strong relationship between researcher (who was also coach in the MBP) and participants may have increased the risk of social desirability bias in that study for some outcomes. However, the study contained rich data on the experience of (self-) acceptance which we judged to be less prone to the influence of social desirability bias and so could be used to understand the link between trust/ safety (context), feeling accepted (mechanism) and outcomes like (self-)compassion. Consistent with realist methodology, ${ }^{42}$ rigour was further judged at the level of explanatory power of the realist programme theory developed in this review. This means, our theory was judged against criteria of consilience (whether it accounted for more of the data than other theories), simplicity (whether it contained as few exceptions as possible) and analogy (whether it fit with what is already known/substantive theory). ${ }^{42}$

\section{Step 5: extracting data and organising findings}

All documents were uploaded into NVivo V.12 (QSR international) to enable a more detailed and systematic analysis. The subsequent coding process was deductive 
and inductive. A first set of codes (called 'nodes' in NVivo) was deductively created in advance, informed by the initial programme theory. New codes were created inductively as new categories with regards to outcomes and potential contexts or mechanisms came up. We first coded qualitative and mixed-methods studies as we found they provided more data with regards to implementation and participants' experiences. After that, we extracted data from quantitative studies, starting with randomised and controlled studies. We then checked all pretestposttest studies to see whether additional relevant data could be identified. Of these, three more studies were included. The remaining studies did not provide any data that we considered to be relevant for theory building and refinement. In other words, we had reached saturation as no new conceptual insights were gained from the data contained within these documents. We stopped coding and extracted the characteristics of all included studies into an Excel spreadsheet. Data extraction was carried out by KM; a random sample of $10 \%$ of the coding was checked independently by GW for consistency.

\section{Step 6: analysing and synthesising data}

Analysis and synthesis were an iterative process. First, we highlighted in each coded piece of data (called 'reference' in NVivo) any passage that had explanatory power. We annotated these passages by briefly summarising the causal processes that we thought were at work. In a next step, we exported all annotations from NVivo into an Excel spreadsheet and broke each of them down into what might be interpreted as functioning as context, mechanism, or outcome. We then started building CMOCs by iteratively moving back and forth between annotations, references and whole documents. Following realist methodology, ${ }^{31}{ }^{40}$ this process involved situating (establishing which mechanisms were activated in which context), juxtaposing (where evidence about what happened in one document enabled insights into outcome patterns of another document), consolidation (building multifaceted explanations of outcomes) and reconciling (identifying differences which explain apparently contradictory sets of findings). We created a node in NVivo for every CMOC and assigned references to CMOC nodes. This process involved iteratively testing and refining our CMOCs until most references had been accounted for. We stopped when we could not build any new CMOCs or refine existing ones from remaining data. All final CMOCs and associated references were exported from NVivo into Microsoft Word.

\section{Retroduction and engagement with substantive theory}

Theory development involved retroduction and engagement with substantive theories. Retroduction is often used in realist approaches and refers to identifying causal mechanisms that might be underlying the emerging patterns yet cannot be directly observed or are not explicit in the existing evidence. ${ }^{43}$ It involves inductive, deductive or abductive (hunch-driven) logic of inference. ${ }^{44}$
Retroduction can be supported by substantive theories from other disciplines to help identify mechanisms or features of context and explain how overall sets of findings fit together. ${ }^{45}$ We had identified two substantive theories from organisational literature (conservation of resources (COR) theory and psychological safety) that we used as explanatory lens through which we interpreted the patterns that our analyses had made visible in the data. One recurrent pattern that had emerged across studies, during coding, were participant quotes related to 'permission' and 'feeling safe', or the lack thereof, in practicing mindfulness at work. Looking for organisational research on psychological safety that would help make sense of these patterns, ${ }^{46}$ we found a reference to COR theory, ${ }^{47}$ which seemed to us to explain one of the more prominent and important parts of what was going on in workplace MBPs. Our choice of substantive theories was guided by what turned out to be the "best fit' for our dataset, that is, it allowed us to synthesise data from a large number of studies covering various settings and programme modalities. More details on our coding, theory development and choice of substantive theories can be found in online supplemental file 3 .

\section{Patient and public involvement}

To focus the scope of this review, stakeholders (one human relations representative, three MBP instructors, one researcher and one potential participant) were informally consulted. To develop an initial programme theory, we consulted existing mindfulness frameworks and KM talked to experts from the field.

\section{RESULTS}

\section{Study characteristics}

In total, we included and coded 75 studies (83 documents, as some studies used multiple research methods and/or resulted in multiple publications) to develop our realist programme theory of workplace MBPs. Of these 83 documents, 38 were randomised controlled trials (RCTs), 22 used qualitative methods and 14 were mixed-method papers. The remaining nine documents were pretestposttest studies, evaluations, reports or articles supplementing individual studies. Seventy-one documents had been identified through literature search and 12 documents came from citation-tracking and other sources (see figure 1). Most studies took place in England and North America. Participants included healthcare professionals ( $44 \%$ of the studies), teachers (11\% of the studies) and professionals from various industries. Delivery formats ranged from face-to-face group settings, to online, selfhelp or blended formats, and individual telephone coaching. Over $50 \%$ of the MBPs were $\geq 8$ weeks long. Over $50 \%$ of the other programmes ran for at least 4 weeks. (Characteristics of the studies included in this review can be found in online supplemental file 4).

\section{Overview of reported outcomes}

Most studies reported significant improvements on one or more measures post intervention and overall positive 


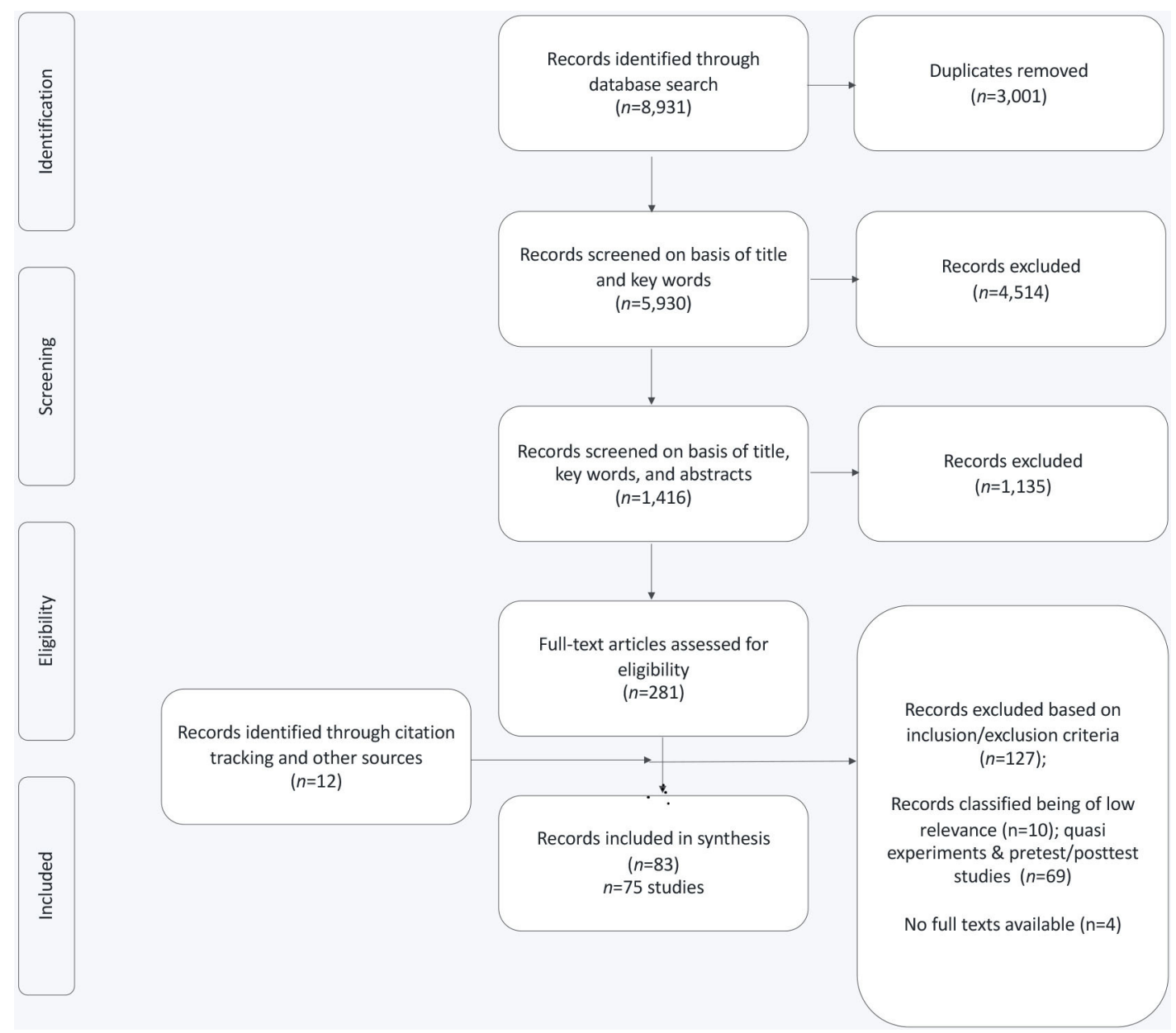

Figure 1 PRISMA flow diagram. PRISMA, Preferred Reporting Items for Systematic Reviews and Meta-Analyses.

course feedback from the participants. However, these results have to be seen in the context of small sample sizes in most quantitative studies. In addition, there was risk of attrition bias. Only one third of the RCTs reported results of intention-to-treat analyses and almost another third did not report sample sizes and attrition at all time points. Likewise, qualitative data were mostly collected from people who volunteered to participate in the research, which might have skewed results towards overly positive views of the programmes.

Significant health-related benefits of workplace MBPs ranged from reductions in perceived stress, anxiety, depression, medical symptoms and burn-out to increased vigour, well-being, quality of life, relaxation, positive emotional states, self-esteem, compassion and improved sleep quality/duration. Reported benefits appeared to be independent of programme format, length and delivery mode. Two RCTs reported no significant changes after the programme. ${ }^{49}{ }^{50}$ Mediation analyses undertaken in the included studies revealed that changes in health-related outcomes were in some cases significantly attributable to changes in mindfulness, ${ }^{51-53}$ in other cases findings were inconsistent. ${ }^{54-57}$

\section{Realist programme theory}

The realist programme theory explains how, why and under what circumstances workplace MBPs achieve the above outcomes. These explanations are expressed as CMOCs (ie, a heuristic used in realist research to describe causal links between context, mechanism and outcome).

Overall, we found that despite of overall positive reports from participants, workplace MBPs can present challenges for participants, at different stages of the programme. At the first stage, management has to offer a mental health/well-being programme at work and employees have to sign up for it. At the second stage, employees have to attend classes and engage with self-care activities in the workplace. At the third stage, participants potentially have to disclose emotional struggles in front of their peers; and, at stage four, they have to integrate new behaviours at work. Our CMOCs are structured around these different stages.

Due to limited space, we only present a brief narrative overview of selected CMOCs that underpin our programme theory, along with illustrative quotes. A full list of all 26 CMOCs can be found in table 2.

A list of all data excerpts linked to each CMOC can be found in online supplemental file 5 . 
Table 2 List of all CMOCs

\section{CMOC Description of CMOC}

\begin{tabular}{ll}
$\begin{array}{l}\text { No of } \\
\text { documents* }\end{array}$ & $\begin{array}{l}\text { No of data } \\
\text { excerpts }\end{array}$ \\
\hline 56 & 594 \\
1 & 10
\end{tabular}

01 In a context where any investment has to produce financial returns (C), a well-being course like an
MBP might trigger concerns of productivity loss (M) with management hesitant to invest in it (O1) or stopping to invest in it (O2) if it does not pay off.

02 In a context where stress and distress are stigmatised (C) participants might be reluctant to sign up for a stress/mental health programme (O1) because they are concerned that they will be seen as weak and vulnerable (M).

03 If an MBP appeals to an organisation's overall business strategy, values, and practices (C) it becomes an attractive investment for management $(\mathrm{O})$ as it is believed to enhance not only health and well-being but also overall productivity and/or work performance (M).

04 In a context where an MBP competes with work tasks $(C)$ employees might be concerned that by attending training sessions and practicing mindfulness they will not be able to attain work related goals (M1) or get their job done (M2) and therefore prioritise work over engagement with the programme and its practices $(\mathrm{O})$.

05 In contexts where employees are under a lot of pressure (C) adding tasks (such as course attendance and home practice) can exacerbate feelings of stress/distress (M) and result in inability to practice mindfulness $(\mathrm{O} 1)$, their dropping-out from the programme $(\mathrm{O} 2)$ and/or lack of beneficial effects (O3).

06 If supervisors do not explicitly support the practice of mindfulness at work $(\mathrm{C})$ employees refrain from doing the exercises $(\mathrm{O})$ because they are concerned that disadvantages might result from 'taking time off for self-care' instead of working (M).

07 In an environment that lacks private or dedicated space for mindfulness practice (C), participants fear interruptions (M1) and might feel exposed in front of non-participating colleagues (M2), which negatively affects their ability to do the practices $(\mathrm{O} 1)$ and reduces their engagement with mindfulness at work (O2).

08 If people are used to taking care of others $(C)$, they might feel guilty about taking time off for themselves $(\mathrm{M})$ and skip training sessions and/or home practice $(\mathrm{O} 1)$ or drop out of the programme (O2).

09 If the MBP competes with private time (C) participants might feel that by attending the training sessions, they have to give up other nourishing activities $(\mathrm{M})$ and they have to make a deliberate choice of what to prioritise (O).

10 If employees are offered an MBP through their employer (C), they see that as a sign of care and appreciation (M1) which enhances their investment in the programme (O1), engagement with the exercises (O2), and the ability to practice mindfulness (O3). Being offered an MBP at work might also facilitate investment in self-care more generally $(\mathrm{O} 4)$ as employees feel that their health and well-being are important (M2).

11 If employees receive official release from their work to attend training sessions $(C)$, they feel 'permitted' to take care of self $(\mathrm{M})$, which facilitates investment in the programme $(\mathrm{O} 1)$, engagement with the exercises $(\mathrm{O} 2)$ and/or the ability to practice mindfulness (O3). Feeling permitted to take care of self can just by itself be relaxing $(\mathrm{O} 4)$ and stress reducing $(\mathrm{O} 5)$, and it might facilitate investment in self-care more generally (O6).

12 When mindfulness practices can be integrated easily into existing routines and busy work schedules $(\mathrm{C})$, take up is high $(\mathrm{O})$ because individuals feel they can do something for their health without having to invest extra time and effort (M1) and/or because it helps them make good use of 'empty' time (eg, wait time, commute time) (M2).

13 In a context where pressure and workloads are high (C1) and/or in moments of immediate stress/ 23

3

6 distress (C2), mindfulness exercises, particularly the brief ones, provide individuals with a sense

$\begin{array}{ll}8 & 11 \\ 7 & 7\end{array}$

7
of coping $(\mathrm{M})$ and thereby reduce perceived stress $(\mathrm{O})$. Coping mechanisms range from attention regulation (M1) and enhanced awareness (M2) to taking a few breaths/deep breathing (M3), cognitive reappraisal (M4), relaxing (M5), zoning out (M6) and/or reminding oneself that these strategies are available (M7).

14 If individuals attend an MBP in their professional roles and functions (C) they might not talk openly 11 about their struggles and experiences $(\mathrm{O})$ because they are concerned that being seen as weak and vulnerable will hurt their professional self $(\mathrm{M})$.

15 When an MBP provides a safe space for professionals to share work related issues (C), receiving 10 practical and emotional support from peers $(\mathrm{M})$ reduces feelings of isolation (O1), enhances normalisation (O2), and might just by itself promote coping (O3) and well-being (O4). 


\section{CMOC Description of CMOC}

16 In a context where participants feel safe to explore emotional difficulties and share them with others (C), normalisation of stress/distress (M1) and the experience of acceptance through group and/or instructor (M2) plant the seeds for greater (self-) acceptance (O1) and (self-) compassion (O2). The experience of acceptance through group and/or instructor can also set the ground for transforming difficult emotions (O2).

17 In a context that allows participants to leave their professional role and status behind (C), they see their own humanity and vulnerability and the same in others $(\mathrm{M})$, which might plant the seed for greater acceptance (O1) and compassion (O2).

18 When the facilitator is trusted and embodies mindful acceptance $(C)$, participants feel safe to explore and test out new ways of being $(\mathrm{M})$ which enables change $(\mathrm{O})$.

19 If mindfulness is seen to be incompatible with work practices (C), individuals might stop investing in it $(\mathrm{O} 1)$ or only use it sporadically $(\mathrm{O} 2)$ because they are concerned that it negatively affects their work performance (M).

20 If participants find their new ways of dealing with workplace stress to be incompatible with workplace culture (C), disillusionment (M1) or concerns about no longer fitting with the team/ organisation (M2) might negatively impact not only their engagement with mindfulness practices (O1) but also overall employee engagement (O2). An MBP can create in-groups and out-groups within an organisation (O3) with employees who have participated in an MBP and those who have not.

21 If participants experience acceptance/compassion in the group and/or in their relationship with the instructor $(\mathrm{C})$, they gain confidence in bringing this experience to difficult moments at work (M) which is experienced as stress reducing $(\mathrm{O} 1)$ and rewarding $(\mathrm{O} 2)$.

22 If employees see colleagues benefiting from the MBP (C), they might feel that they 'want this too' (M) leading to contagion effects with more and more people getting involved with mindfulness in an organisation (O).

23 If an MBP is offered as a professional development programme (C1) or otherwise appeals to an

No of No of data documents* excerpts†
1752
1752 individual's professional aspirations, values, or practices (C2) it becomes a worthwhile investment $(\mathrm{O})$ as it is seen to enhance not only mental health and well-being but also professional functioning and development $(\mathrm{M})$ and/or to help achieve workplace goals $(\mathrm{M})$.

24 When the teachings help participants make sense of their experience $(C)$ they provide a sense of growth (M1) and/or control (M2) which positively affects engagement with the MBP and its practices (O).

25 If participants experience improvements that they attribute to their mindfulness practice (C) they continue practicing $(\mathrm{O})$ because they feel that they will be OK as long as they do the exercises (M1) and/or might improve even more (M2). This might create feedback loops (O2) or even set off gain spirals (O2).

26 Positive effects in one area (C) can have a ripple effect leading to improvements in other areas (O) 21
as individuals feel they have more energy at their disposal (M1), they have gained confidence in
themselves and in the mindfulness approach (M2), they are better able to regulate their emotions
and behaviour (M3) and/or increased awareness encourages them to take better care of their
health (M4).

*Number of documents in which we found data to support that specific CMOC.

†Number of data excerpts that were used to build that specific CMOC.

CMOCs, context-mechanism-outcome configurations.

Stage 1: management offer and employees' acceptance of a mental health and well-being programme (CMOCs 1-3)

In a context where any investment has to produce financial returns $(\mathrm{C})$, a well-being course like an MBP can trigger concerns of productivity loss $(\mathrm{M})$ with management hesitant to invest in it (O1) or stopping to invest in it (O2) if it does not pay off (CMOC 1):

I'm still figuring out what mindfulness is all about and how it can fit into our business model. [...] I'll have to find some way to prove that the program works if we are to continue with it onwards. It's just the reality. Controller, Accounting Firm ${ }^{58}$

However, if the MBP appeals to an organisation's overall business strategy, values and practices $(\mathrm{C})$ it becomes an attractive investment for management $(\mathrm{O})$ as it is believed to enhance not only health and well-being but also overall productivity and/or work performance (M) (CMOC 3):

So, I felt a program like this one would be an important piece of caring for nurses, which I believe will 
ultimately pay off in the way they care for patients. Vice President, Hospital ${ }^{59}$

Likewise, employees feel more comfortable signing up for an MBP, if it is promoted as professional development programme und thus promises professional/personal growth or attainment of goals (see CMOC 23). Employees may be reluctant to sign up for a stress/mental health programme $(\mathrm{O} 1)$ in a context where stress and distress are being stigmatised $(\mathrm{C})$ because they are concerned that they might be seen as weak and vulnerable (M) (CMOC 2). At the same time though, being offered a mental health/well-being intervention at work is seen to have the potential to reduce the stigmatisation of weakness and vulnerability in the workplace. ${ }^{60}$

\section{Stage 2: acceptance to take on self-care (CMOCs 4-13)}

If employees are offered an MBP through their employer (C), they see that as a sign of care and appreciation (M1) which enhances their investment in the programme $(\mathrm{O} 1)$, engagement with the exercises $(\mathrm{O} 2)$ and the ability to practice mindfulness (O3) (CMOC 10). Being offered an MBP at work might also facilitate investment in selfcare more generally $(\mathrm{O} 4)$ as employees feel that their health and well-being are important (M2):

[...] the fact that the University ran the course seemed to be saying it's okay to take care of yourself; it gave you the right to do it [...]. Participant, University Employee ${ }^{61}$

At the same time, though, if an MBP competes with work tasks (C), employees might be concerned that by attending training sessions and practising mindfulness they will not be able to attain work related goals (M1) or get their job done (M2) (CMOC 4). They might, therefore, prioritise work over engagement with the MBP and its practices $(\mathrm{O})$ even if they believe in the benefits of the programme:

One dropout told me that he had performed a mental cost-benefit analysis and, while he realized that the course would be beneficial to him in the long run, he reasoned that the pressing needs of his parish had to come first. ${ }^{62}$

If employees' supervisors do not explicitly support the practice of mindfulness at work (C) employees may refrain from attending classes and doing the exercises (O) because they are concerned that disadvantages might result from 'taking time off for self-care' instead of working (M) (CMOC 6). Yet, supervisor support itself may not be enough; participants need protected time to attend training sessions. One large RCT found that only perceived facilitation by the supervisor (eg, allowing flexible handling of working hours) was associated with high compliance, whereas perceived supervisor support of participation was not. ${ }^{63}$

In contexts where employees are already under a lot of work pressures (C) adding tasks (such as course attendance and home practice) can even exacerbate feelings of stress/distress (M) and result in inability to practice mindfulness (O1), dropping-out from the programme (O2) and/or lack of beneficial effects (O3) (CMOC 5). However, there were also examples where employees improved significantly despite of above average baseline levels of stress/distress or burn-out. ${ }^{64-68}$ The reasons for these inconsistencies could not be identified from the included documents.

If employees receive official release from their work to attend training sessions $(\mathrm{C})$, they feel 'permitted' to take care of self $(\mathrm{M})$, which facilitates investment in the programme $(\mathrm{O} 1)$, engagement with the exercises $(\mathrm{O} 2)$ and/or the ability to practice mindfulness (O3) (CMOC 11). Feeling permitted to take care of self can just by itself be relaxing $(\mathrm{O} 4)$ and stress reducing $(\mathrm{O} 5)$, and it might facilitate investment in self-care more generally $(\mathrm{O} 6)$.

Take up of mindfulness practices is generally high $(\mathrm{O})$, when practices can be integrated easily into existing routines and busy work schedules $(\mathrm{C})$, because individuals feel they can do something for their health without having to invest extra time and effort (M1) or make good use of 'empty' time (eg, wait time, commute time) (M2) (CMOC 12). In a context where pressure and workloads are high (C1) and/or in moments of immediate stress/ distress (C2), mindfulness exercises, particularly the brief ones, provide individuals with a sense of coping $(\mathrm{M})$ and thereby reduce perceived stress $(\mathrm{O})$. Coping mechanisms range from attention regulation (M1) and enhanced awareness (M2) to taking a few breaths/deep breathing (M3), cognitive reappraisal (M4), relaxing (M5), zoning out (M6) and/or reminding oneself that these strategies are available (M7) (CMOC 13):

The techniques of looking at shades of green when driving in the car certainly helps me stressing out in traffic. Participant, Health Care ${ }^{69}$

And the techs $[\ldots]$ and $[\ldots]$ some of the nurses, too, have said that they really appreciate when they get to participate in the mindfulness moments, but even ... when they don't [...], kind of knowing that it's available to, like a chance to take a threeminute break and calm down $[\ldots]$. Facilitator, Health Care ${ }^{70}$

Apart from protected time, protected space is an issue in workplace MBPs. In an environment that lacks private or dedicated space for mindfulness practice (C), participants fear interruptions (M1) and might feel exposed in front of non-participating colleagues (M2), which negatively affects their ability to do the practices (O1) and reduces their engagement with mindfulness at work $(\mathrm{O} 2)$ (CMOC 7):

(The) socialized mind never really quite settles down when you realize that there are other people observing you. Participant, Health Care C1 $^{71}$

In one study, teams conducted brief mindfulness meditations before their stand-up meetings, which significantly 
enhanced subsequent meeting effectiveness and team cooperation. ${ }^{72}$ However, they discontinued the exercises because they felt uncomfortable doing them in a public setting.

\section{Stage 3: acceptability of showing weakness and vulnerability (CMOCs 14-18)}

It is not uncommon for individuals to experience unpleasant sensations (eg, pain, tension, restlessness) or difficult emotions (eg, sadness, irritability, boredom) during mindfulness meditation. ${ }^{58} 61$ 71 73-78 Becoming aware of these difficulties and exploring them in an open, kind-hearted way is a central learning element in practicing mindfulness. For this learning to happen, participants need to let go of mastery and perfectionism and open up to their struggles. This can be a challenge in a workplace setting. If individuals attend an MBP in their professional roles and functions $(\mathrm{C})$, they might be concerned that being seen as weak and vulnerable will hurt their professional self $(\mathrm{M})$ and therefore not share their struggles $(\mathrm{O})$ (CMOC 14).

But, in a context where participants feel safe to explore emotional difficulties and share them with others $(\mathrm{C})$, normalisation of stress/distress (M1) and the experience of acceptance through group and/or instructor (M2) plant the seeds for greater acceptance (O1) and compassion (O2) (CMOC16). In one study that took place in a palliative care setting, a participant talked about high anxiety levels during meditation. The instructor took the opportunity to explain "how common it is for all of us to feel anxious," which was perceived as "very useful to the group as it normalized not having a calm mind [...]..$^{179}$ One participant from the same study summarised her learning experience postintervention:

I was hoping $[\ldots]$ that the mediation would make my discomfort lessen. But what I have in fact noticed is that my awareness of discomfort has shifted. Now I simply notice that I am not feeling comfortable! [...] So it's a worldview shift to just accepting things. ${ }^{79}$

Acceptance (O1) and compassion (O2) also emerge in a context, where participants can leave their professional role and status behind $(\mathrm{C})$ because they see their own humanity and vulnerability and the same in others (M) (CMOC 17):

It was interesting, because as much as it can be logical to yes have only doctors together to observe things, to go further, to dig deeper... it's also good for the doctors to realize that what it boils down to is a human being in front of another human being. Participant, Health Care ${ }^{77}$

It helped me bring out more compassion towards the doctors $[\ldots]$ I find it interesting to see how they get caught in that grind and in those difficulties. It touched me a great deal to see how difficult it is and I think that was important for me. Participant, Health Care $^{77}$
Stage 4: integrating new behaviours at work (CMOCs 19-22)

In order to integrate new behaviours at work, individuals need to feel comfortable doing so. Those participants who experienced acceptance/compassion in the group or in their relationship with the instructor (C), have gained confidence in bringing this experience to difficult moments at work (M) which is experienced as stress reducing $(\mathrm{O} 1)$ and rewarding $(\mathrm{O} 2)$ (CMOC 21):

I would be so empathetic [...] and I would be just wiped out [...] It's not that I don't empathize with them anymore, but (now) I feel OK just to listen and be present with them $[\ldots]$ and that is a wonderful thing that you can do for patients [...]. I just needed to learn that myself [...]. Participant, Health Care ${ }^{80}$

Whether individuals use what they learnt in an MBP also depends on the compatibility of mindfulness with work practices and work environment. If mindfulness is seen to be incompatible with work practices $(\mathrm{C})$, individuals stop investing in it (O1) or only use it sporadically (O2) as they are concerned that it negatively affects their work performance (M) (CMOC 19). Disillusionment (M1) or concerns about no longer fitting with the team/organisation (M2) might not only reduce ongoing engagement with mindfulness practices $(\mathrm{O} 1)$ but have a negative impact on overall employee engagement $(\mathrm{O} 2)$ (CMOC 20).

\section{All stages (CMOCs 23-26)}

Some CMOCs apply to all stages of a workplace MBP. For instance, individuals engage through all stages with an MBP $(\mathrm{O})$ if it is offered as a professional development programme $(\mathrm{C} 1)$ or otherwise appeals to an individual's aspirations, values or practices (C2). In these cases, the MBP promises to enhance not only mental health and well-being but also professional functioning and development (M) and/or to help achieve workplace goals (M) (CMOC 23):

A sense of professional authenticity was voiced by several participants as they felt more comfortable conducting the relaxation activities in the grief support program manual, and more confident in adapting those activities to the needs of each grief group and group member. ${ }^{81}$

Participants also continue to engage with mindfulness practices (O1) if they experience improvements that they attribute to these practices $(\mathrm{C})$, because they feel that as long as they continue doing them, they will be OK (M1) and/or improve even more (M2) (CMOC 25). This might create feedback loops $(\mathrm{O} 2)$ or even set off gain spirals (O3). Positive effects in one area $(\mathrm{C})$ can have a ripple effect and lead to improvements in other areas $(\mathrm{O})$ as individuals feel they have more energy at their disposal (M1), they have gained confidence in themselves and in the mindfulness approach (M2), they are better able to regulate their emotions and behaviour (M3) and/or 


\section{Box 2 Psychological safety}

The construct of psychological safety is based on Schein and Bennis' ${ }^{96}$ work on organisational change and has been defined as 'feeling able to show and employ one's self without fear of negative consequences to self-image, status or career. ${ }^{, 97}$ A psychologically safe work environment has been described as an environment where employees are not rejected for being themselves or saying what they think but, rather, are interested in each other as human beings and they feel safe to experiment and take risks. ${ }^{46}$ Findings from organisational research support the notion that a safe environment is crucial for experiential learning where individuals are required to take risks and try out new and unproven ideas. ${ }^{98}$ Psychological safety has been shown to play an important role in implementing new and innovative approaches at work. ${ }^{469}$ One of the mechanisms by which psychological safety yields its positive effects in organisations may be that it motivates individuals to invest resources, thereby linking psychological safety to conservation of resources theory. ${ }^{46}$

increased awareness encourages them to take better care of their health (M4) (CMOC 26).

In summary, at each stage, there are a common 'family' of mechanisms' (feeling assured, permitted, safe, confident or comfortable) that unlock subsequent engagement with the MBP and mindfulness. At the same time, various forms of concerns (eg, concern of not getting work done, of being seen as weak and vulnerable, or of no longer fitting with the team) might prevent individuals from fully engaging with the programme and mindfulness. Other mechanisms that drive adherence with the programme and its activities are a 'sense of growth' and 'promise of goal attainment.'

\section{Bringing existing theories into our realist programme theory}

We used the theory of psychological safety (box 2) and COR theory (box 3) as theoretical lenses through which to interpret the data from the reviewed literature and develop a realist programme theory from our initial programme theory. Our realist programme theory can be found in box 4 (see also figure 2).

\section{DISCUSSION}

\section{Summary of findings}

Findings from this realist review suggest that workplace MBPs enable participants (including healthcare professionals) to deal more skillfully with stressful events and improve their well-being. The mechanisms involved can be grouped around awareness/self-regulation, acceptance/compassion, feeling permitted to take care of self, sense of growth and promise of goal attainment. In order for professionals to invest in an MBP and benefit from it, it is important that they feel safe to engage with self-care at work and share emotional difficulties among peers. It is also important that employees are able to link the programme and its activities to existing goals and practices. Concerns of being non-productive, of not getting work done or of being exposed in front of colleagues can

\section{Box 3 Conservation of resources theory}

Conservation of resources (COR) theory is one of the most widely used theories to conceptualise stress, burn-out and motivation in organisations. It is based on the idea that humans strive to protect existing resources and acquire new resources. The term 'resource,' within COR theory, can refer to anything a person values. ${ }^{47}$ Refinements of that definition suggest that the value of a resource depends on: (1) the extent to which it is seen to help an individual attain their goals; (2) whether it complements existing resources and (3) whether an individual has enough internal or external resources (eg, health or social support) to be able to acquire and use that new resource. ${ }^{100}$ The value of a resource is thus determined by a range of individual, social and situational factors, and individuals with greater resources are more capable of resource gain (which might set of a gain spiral). COR theory further proposes that due to evolutionary survival mechanisms threat to existing resources is psychologically more harmful for individuals than resource gain is beneficial (primacy of loss principle). ${ }^{100}{ }^{101}$ As a consequence, individuals tend to protect current resources before they invest in the acquisition of new ones. Individuals may also refer to strategic use of resources as a form of protective behaviour. In summary, COR theory attempts to understand how individuals allocate and conserve resources in the context of resource gains and losses. It assumes that it is not necessarily the individual with the most resources that will thrive but the one that is best able to allocate those resources to maximise their fit with the environment. ${ }^{100}$

result in strategic use of brief mindfulness exercises, nonadherence or drop-out.

\section{Strengths, limitations and future directions}

In conducting our realist review, we followed the RAMESES quality standards for realist reviews. ${ }^{40}$ The explanations from the refined programme theory are based on understanding the behaviour of widely occurring mechanisms under different contexts and on data from documents that include a broad range of professional groups. This provides a warrant for transferability of the findings and is one of the strengths of this realist review.

In applying a realist approach to synthesising existing evidence on workplace MBPs, we identified three mechanisms ('feeling permitted to take care of self,' 'sense of growth' and 'promise of goal attainment') that go beyond the mechanisms of change proposed by our initial official programme theory of MBPs. Future research should determine in how far these additional mechanisms not only enhance programme engagement but also mental health and well-being. Personal growth and purpose, for instance, have been defined as categories of wellbeing. ${ }^{82} 83$

This is the first review on workplace MBPs where outcomes have been explained using COR theory. In contrast to the more often cited stress appraisal theory by Lazarus and Folkman ${ }^{84}$ that mainly looks at individual stress perception, COR theory provides a broader and more consilient explanation of MBPs as it explores how individuals allocate and conserve resources in the context of resource gains and losses. Applying COR theory to workplace MBPs leads to the following questions that warrant 
Box 4 Realist programme theory of workplace mindfulness-based programmes (MBPs)

Workplace MBPs help individuals build resources to be better able to deal with stress/distress and enhance well-being. Yet, in order to build these resources, participants (and management) have to invest resources (eg, time, money, and energy). Moreover, by investing in an MBP at work, employees might put existing resources, such as completing work tasks, image of strength and perfection, or fitting with the team at risk. As a consequence, they have to weigh the benefits of developing new resources against the threat of potential resource loss. In line with conservation of resources (COR) theory, individuals seem to be more likely to invest in a workplace MBP if: (1) the programme is seen to help them attain goals; (2) mindfulness complements existing resources and (3) the environment is supportive of their engagement with the programme. In order for an environment to be perceived as supportive, it is particularly important that employees feel safe. At each stage of an MBP, psychological safety functions as 'door opener' for the subsequent, extended or deepened engagement with the programme. 'Feeling safe' in the group or in relation to the MBP instructor might be important for the development of acceptance/compassion and subsequently, for bringing mindfulness to challenging work situations.

Applying COR theory to workplace MBPs suggests that, if the environment is not supportive, employees might prefer to protect current resources (ie, time for work, status, free time) instead of investing in the development of new ones (ie, mindfulness). They might use mindfulness strategically (eg, combining brief exercises with other routines or using breathing techniques for coping in stressful situations), which may benefit them but perhaps not as much when compared with deeper engagement. If, on the other hand, an MBP is seen to fit with an individual's or organisation's goals, if it complements existing resources and if the setting is perceived as safe, a workplace MBP might set off gain spirals with positive impact on a wide range of well-being outcomes.

further investigation: Do those individuals who invest most in a workplace MBP (and develop deeper levels of mindfulness) also improve the most? Or do the ones who best allocate their resources thrive most? When do above average baseline levels of stress/distress exacerbate stress in individuals? When do those individuals who are most stressed prior to the course also benefit most from it? A better understanding of the interplay between resource investment and outcome has implications for the implementation and design (eg, length and intensity) of workplace MBPs.

As one major limitation, our review is based on data that originally had not been collected for realist synthesis. Hence interpretative work was needed to develop our CMOCs. In addition, in developing our programme theory, we had to link data from a large variety of studies and existing theory. The plausibility of our inferences would be strengthened if we had more primary data that specifically focused on aspects of our realist programme theory. While the relative consistent occurrence of certain patterns across studies speaks for the robustness of most of our CMOCs, more realist work is needed to test them. Unfortunately, the available data from included documents did not allow us to unpack many of the healthrelated outcomes, particularly those that manifest further down the outcome chain (eg, improved sleep and medical symptoms, reduced anxiety, depression, burn-out). This is a clear limitation and requires further research.

The explanations that we provide for outcomes of workplace MBPs are semipredictable. This means, variations in outcome patterns can only partly be attributed to variations in context from one setting to another. ${ }^{40}$ For example, whether participants feel 'safe' will most probably not only depend on the setting but also differ between participants of one and the same programme. The same applies to non-compliance. There are presumably multiple reasons why people do not do the exercises or drop out of a programme. Our realist review has been able to shed light on this issue through its CMOCs, but we do not claim to have developed an exhaustive and definitive explanation of all outcomes from MBPs. As with any complex intervention working in an open social system

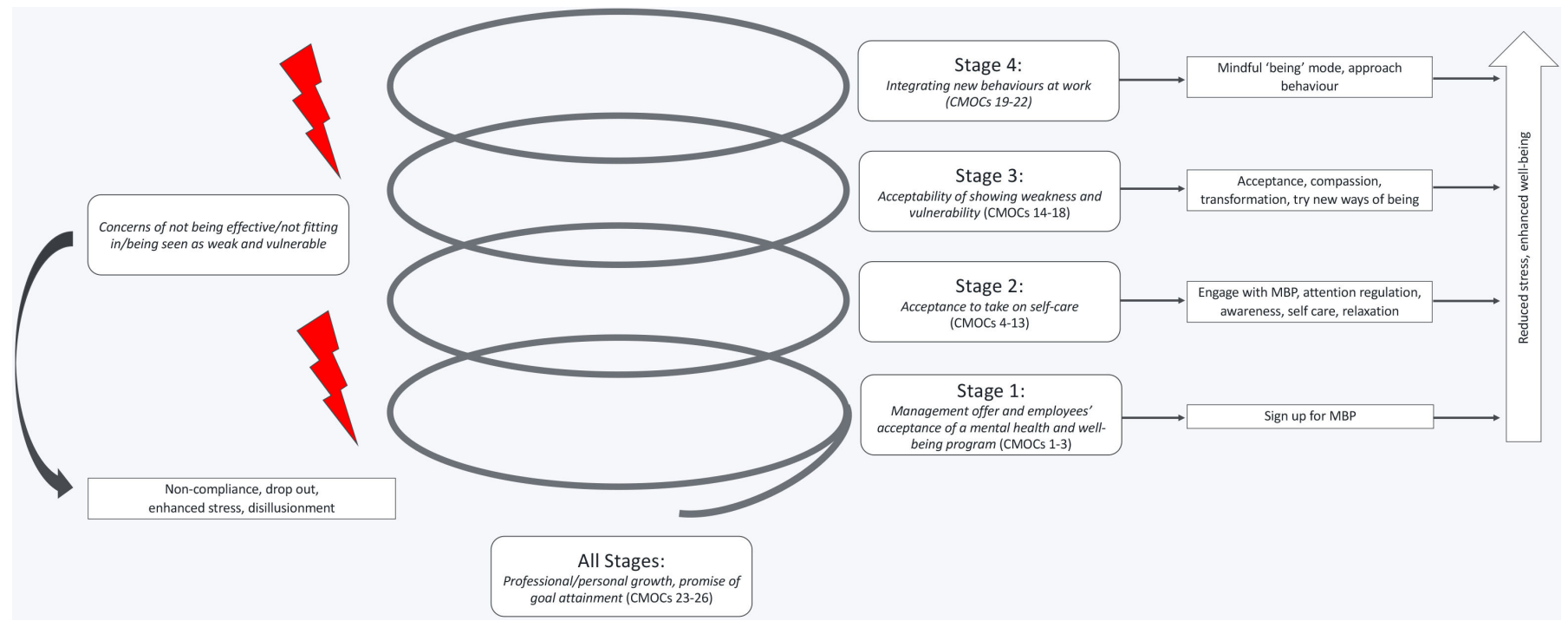

Figure 2 Realist programme theory of workplace MBPs.CMOCs, context-mechanism-outcome configurations; MBPs, mindfulness-based programmes. 
there are most likely additional explanations for the observed outcomes in workplace MBPs, which will need further research to address.

\section{Comparison with existing literature}

In applying a realist approach to knowledge synthesis, our review confirms some of the findings from previous reviews and moves beyond existing knowledge. Our programme theory is in line with Good et al s framework $^{29}$ of workplace MBPs in supporting their notion that participants of workplace MBPs learn to regulate their attention, emotions and behaviour. Surprisingly though, a recent meta-analysis by Lomas $e t a l^{25}$ found only small and non-significant effects of workplace MBPs on emotion regulation. The reasons for these inconsistencies are not clear.

Other reviews have recognised the potential influence of context on outcomes in workplace MBPs ${ }^{11} 23298586$ yet, no previous review has systematically explored it. In their review of brief ( $\leq 4$ hour) MBPs for healthcare professionals, Gilmartin $e t a l^{87}$ pointed out that among those programmes that most successfully improved participants' well-being were those that had adapted course hours to work schedules, provided protected space for practice and/or were compatible with the respective work culture. This accords with our theory. Future research should investigate whether the 'right' context might be as important for the success of a workplace MBP as its length.

In his framework of mindfulness as on-the-spot workplace intervention, Hafenbrack ${ }^{88}$ proposes that short attention regulation exercises in the face of acute stress might be enough, if not even more feasible, than the practice of non-judgmental acceptance in a workplace setting. Our programme theory accords with Hafenbrack's framework yet, extends it by showing in which contexts acceptance (as part of the mindful 'being mode') might provide professionals with a helpful resource at work. A more systematic depiction of how professionals employ the mindful 'being' in the workplace can be found in Lyddy and Good. ${ }^{89}$

Morgan $e t a l^{21}$ conclude in their qualitative review of MBPs that overcoming challenges related to mindfulness practice might have been among the factors that helped healthcare workers increase acceptance and compassion for self and others. Our programme theory aligns with their findings. It adds a deeper understanding of the context that enables the development of compassion in a workplace MBP. This has important implications, as compassion has been linked to protection against compassion fatigue in healthcare professionals ${ }^{90}$ and to improved patient relations. ${ }^{25}$ Our theory needs to be treated with caution though. There is some evidence that enhanced workplace compassion in mindfulness practitioners might be linked to long-term (Buddhist) meditation practice. ${ }^{81}$ A recent meta-analysis found that enhanced compassion in healthcare professionals was associated with standardised 8-week mindfulness-based stress reduction programmes ${ }^{25}$ which warrants further investigation of how and why individuals develop compassion in workplace MBPs.

Morgan et al have further pointed out that one of the pitfalls of mindfulness training in a professional setting might be that people do not engage on a personal level with the practices but rather see them as tools that they can apply with their own patients. Findings from our review partially support this, however, we also found that people engaged more and at a deeper level with the MBP if they were also able to use mindfulness in their professional practice as therapist, counsellors, teachers or leaders.

Finally, previous research has demonstrated how feedback loops and gain spirals might contribute to the positive effects of MBPs. ${ }^{92}{ }^{93}$ More recently, a study by Hülsheger $e t a l^{4}$ on state mindfulness in working populations showed how previous day recovery experiences benefitted mindfulness and subsequent recovery experience (gain spiral), whereas workload hampered the experience of mindfulness as well as subsequent recovery experience (loss spiral). Findings from our review support these observations by proposing that resource gains and losses in workplace MBPs may have to be seen in the context of resource availability. The theory that employees (and organisations) may prefer resource protection over resource acquisition has been supported by existing organisational research. For example, meta-analytical evidence on voice behaviour at work $^{95}$ found that employees who face major workplace stress tend to shy away from expressing changeoriented ideas and suggestions because they find it too depleting.

\section{Conclusion}

Simply offering an MBP to (healthcare) professionals in order to reduce stress and enhance well-being does not suffice. A supportive environment must exist in order for the programme's benefits to be reaped. With the increasing offer of MBPs to healthcare professionals and a plethora of promises of related health and performance benefits, our programme theory may help orient those who are less versed in the field about what might (and what might not) work, for whom, and under what circumstances. Based on our findings, we have developed four key recommendations that should be taken into consideration when designing and implementing workplace MBPs. These recommendations are 'generic' enough to be applied, with minor local adaptions, across different healthcare settings, other sectors, target groups and programme types.

- Make mindfulness compatible with participants' and organisational goals, values and practices.

- Provide protected time and space for individuals to engage in self-care activities.

- Create an environment where individuals feel safe to share and learn. 
- Offer a short programme with brief coping techniques, if the above recommendations cannot be met or can only be partially met.

Acknowledgements We would like to thank the group of stakeholders and content experts who gave their time and expertise to the study.

Contributors KM made substantial contributions to the acquisition of data, analysis, interpretation of data and drafting of the manuscript for important intellectual content. GW and JH made substantial contributions to the conception and design and analysis and interpretation of data and are involved in revising the manuscript for important intellectual content. All authors read and approved the final manuscript.

Funding Geoff Wong's salary is partly supported by The Evidence Synthesis Working Group of the National Institute for Health Research School for Primary Care Research (NIHR SPCR) [Project Number 390]. The views expressed are those of the author(s) and not necessarily those of the NIHR, the NHS or the Department of Health.

Competing interests KM delivers workplace MBPs and receives honoraria or fees for lectures, workshops, courses and/or educational presentations on mindfulness. She does not receive any financial support from any of her clients for her research and has no commercial interest in publishing and disseminating the results. GW and $\mathrm{JH}$ have no financial or professional interest in the subject matter of this review.

Patient consent for publication Not required.

Provenance and peer review Not commissioned; externally peer reviewed.

Data availability statement All data relevant to the study are included in the article or uploaded as online supplemental information.

Supplemental material This content has been supplied by the author(s). It has not been vetted by BMJ Publishing Group Limited (BMJ) and may not have been peer-reviewed. Any opinions or recommendations discussed are solely those of the author(s) and are not endorsed by BMJ. BMJ disclaims all liability and responsibility arising from any reliance placed on the content. Where the content includes any translated material, BMJ does not warrant the accuracy and reliability of the translations (including but not limited to local regulations, clinical guidelines, terminology, drug names and drug dosages), and is not responsible for any error and/or omissions arising from translation and adaptation or otherwise.

Open access This is an open access article distributed in accordance with the Creative Commons Attribution Non Commercial (CC BY-NC 4.0) license, which permits others to distribute, remix, adapt, build upon this work non-commercially, and license their derivative works on different terms, provided the original work is properly cited, appropriate credit is given, any changes made indicated, and the use is non-commercial. See: http://creativecommons.org/licenses/by-nc/4.0/.

\section{ORCID iDs}

Katrin Micklitz http://orcid.org/0000-0002-6465-0307

Geoff Wong http://orcid.org/0000-0002-5384-4157

Jeremy Howick http://orcid.org/0000-0003-0280-7206

\section{REFERENCES}

1 Hassard J, Teoh KRH, Visockaite G, et al. The cost of work-related stress to society: a systematic review. J Occup Health Psychol 2018;23:1-17.

2 EU-OSHA. Calculating the costs of work-related stress and psychosocial risks: a literature review. Luxembourg: Publications Office of the European Union, 2014.

3 Davies SC. Annual report of the chief medical officer 2013, public mental health priorities: investing in the evidence. London: Department of Health, 2014.

4 McKinley N, McCain RS, Convie L, et al. Resilience, burnout and coping mechanisms in UK doctors: a cross-sectional study. BMJ Open 2020;10:e031765.

5 Lemaire JB, Wallace JE. Burnout among doctors. BMJ 2017;358:j3360.

6 Bagnall A, Jones R, Akter $\mathrm{H}$. Interventions to prevent burnout in high risk individuals: evidence review. Public Health Eng 2016.

7 Leka S, Jain A. Mental health in the workplace in Europe. European Comission, 2019

8 Mindful Nation UK. Mindfulness all-party parliamentary group, 2015.
9 The Mindfulness Initiative. Building the case for mindfulness in the workplace, 2016. Available: https://www.themindfulnessinitiative. org/Handlers/Download.ashx?IDMF=46ef10fd-4d64-41f9-91a6163d52cd304c

10 Brown KW, Ryan RM, Creswell JD. Mindfulness: theoretical foundations and evidence for its salutary effects. Psychol Inq 2007;18:211-37.

11 Bartlett L, Martin A, Neil AL, et al. A systematic review and metaanalysis of workplace mindfulness training randomized controlled trials. J Occup Health Psychol 2019;24:108-26.

12 Lomas T, Medina JC, Ivtzan I, et al. Mindfulness-based interventions in the workplace: an inclusive systematic review and meta-analysis of their impact upon wellbeing. $J$ Posit Psychol 2019;14:625-40.

13 Vonderlin R, Biermann M, Bohus M, et al. Mindfulness-based programs in the workplace: a meta-analysis of randomized controlled trials. Mindfulness 2020;11:1579-98.

14 Slemp GR, Jach HK, Chia A, et al. Contemplative interventions and employee distress: a meta-analysis. Stress Health 2019;35:227-55.

15 Lomas T, Medina JC, Ivtzan I, et al. The impact of mindfulness on well-being and performance in the workplace: an inclusive systematic review of the empirical literature. Europ $J$ Work Organizat Psychol 2017;26:492-513.

16 Janssen M, Heerkens Y, Kuijer W, et al. Effects of mindfulnessbased stress reduction on employees' mental health: a systematic review. PLoS One 2018;13:e0191332.

17 Irving JA, Dobkin PL, Park J. Cultivating mindfulness in health care professionals: a review of empirical studies of mindfulnessbased stress reduction (MBSR). Complement Ther Clin Pract 2009;15:61-6.

18 Smith SA. Mindfulness-based stress reduction: an intervention to enhance the effectiveness of Nurses' coping with work-related stress. Int J Nurs Knowl 2014;25:119-30.

19 Guillaumie L, Boiral O, Champagne J. A mixed-methods systematic review of the effects of mindfulness on nurses. J Adv Nurs 2017;73:1017-34.

20 Lomas T, Medina JC, Ivtzan I, et al. A systematic review of the impact of mindfulness on the well-being of healthcare professionals. $J$ Clin Psychol 2018;74:319-55.

21 Morgan P, Simpson J, Smith A. Health care workers' experiences of mindfulness training: a qualitative review. Mindfulness 2015;6:744-58.

22 Regehr C, Glancy D, Pitts A, et al. Interventions to reduce the consequences of stress in physicians: a review and meta-analysis. $J$ Nerv Ment Dis 2014;202:353-9.

23 Burton A, Burgess C, Dean S, et al. How effective are mindfulnessbased interventions for reducing stress among healthcare professionals? A systematic review and meta-analysis. Stress Health 2017;33:3-13.

24 Ruiz-Fernández MD, Ortíz-Amo R, Ortega-Galán ÁM, et al. Mindfulness therapies on health professionals. Int $J$ Ment Health Nurs 2020;29:127-40.

25 Lomas T, Medina JC, Ivtzan I, et al. A systematic review and meta-analysis of the impact of mindfulness-based interventions on the well-being of healthcare professionals. Mindfulness 2019;10:1193-216.

26 Suleiman-Martos N, Gomez-Urquiza JL, Aguayo-Estremera R, et al. The effect of mindfulness training on burnout syndrome in nursing: a systematic review and meta-analysis. J Adv Nurs 2020;76:1124-40.

27 Spinelli C, Wisener M, Khoury B. Mindfulness training for healthcare professionals and trainees: a meta-analysis of randomized controlled trials. J Psychosom Res 2019;120:29-38.

28 Wasson RS, Barratt C, O'Brien WH. Effects of mindfulness-based interventions on self-compassion in health care professionals: a meta-analysis. Mindfulness 2020;11:1914-34.

29 Good DJ, Lyddy CJ, Glomb TM, et al. Contemplating mindfulness at work. J Manage 2016;42:114-42.

30 Klingbeil DA, Renshaw TL. Mindfulness-based interventions for teachers: a meta-analysis of the emerging evidence base. Sch Psychol Q 2018;33:501-11.

31 Pawson R. Evidence-Based policy: a realist perspective. London: Sage Publications, 2006.

32 et alGreenhalgh T, Pawson R, Wong G. Realist evaluation, realist synthesis, realist research - what's in a name? The RAMESES II Project, 2017. Available: https://www.ramesesproject.org/media/ RAMESES_II_RE_RS_RR_whats_in_a_name.pdf [Accessed $3 \mathrm{Apr}$ 2020].

33 Craig P, Dieppe P, Macintyre S, et al. Developing and evaluating complex interventions: the new medical Research Council guidance. BMJ 2008;337:a1655. 
34 van der Velden AM, Kuyken W, Wattar U, et al. A systematic review of mechanisms of change in mindfulness-based cognitive therapy in the treatment of recurrent major depressive disorder. Clin Psychol Rev 2015;37:26-39.

35 Alsubaie M, Abbott R, Dunn B, et al. Mechanisms of action in mindfulness-based cognitive therapy (MBCT) and mindfulnessbased stress reduction (MBSR) in people with physical and/or psychological conditions: a systematic review. Clin Psychol Rev 2017;55:74-91.

$36 \mathrm{Gu}$ J, Strauss C, Bond R, et al. How do mindfulness-based cognitive therapy and mindfulness-based stress reduction improve mental health and wellbeing? A systematic review and metaanalysis of mediation studies. Clin Psychol Rev 2015;37:1-12.

37 Rupprecht S, Koole W, Chaskalson M, et al. Running too far ahead? Towards a broader understanding of mindfulness in organisations. Curr Opin Psychol 2019;28:32-6.

38 Wong G, Greenhalgh T, Westhorp G. RAMESES publication standards: realist syntheses. BMC Med 2013;11.

39 Crane RS, Brewer J, Feldman C, et al. What defines mindfulnessbased programs? the warp and the weft. Psychol Med 2017;47:990-9

40 Wong G, Westhorp G, Pawson R. Realist synthesis RAMESES training materials. The Rameses projects, 2013. Available: https:// www.ramesesproject.org/media/Realist_reviews_training_materials. pdf [Accessed 6 May 2019].

41 Linger RA. A qualitative study of a mindfulness-based coaching intervention for perception shifts and emotional regulation around workplace stressors and quality of Worklife. PHD thesis. Pasadena: Saybrook University, 2016.

42 Wong G. Data gathering for realist reviews: looking for needles in haystacks. In: Emmel N, Greenhalgh J, Manzano A, et al, eds. Doing realist research. London: Sage, 2018: 131-45

43 Greenhalgh T, Pawson R, Wong G. Retroduction in realist evaluation. The RAMESES II project, 2017. Available: https:// www.ramesesproject.org/media/RAMESES_II_Retroduction.pdf [Accessed 3 Mar 2020].

44 Jagosh J. Retroductive theorizing in Pawson and Tilley's applied scientific realism. J Crit Realism 2020;19:121-30.

45 Greenhalgh T, Pawson R, Wong G. "Theory" in realist evaluation. The RAMESES II Project, 2017. Available: http://www. ramesesproject.org/media/RAMESES_II_Theory_in_realist_ evaluation.pdf [Accessed 19 Jun 2019].

46 Newman A, Donohue R, Eva N. Psychological safety: a systematic review of the literature. Human Res Manag Rev 2017;27:521-35.

47 Hobfoll SE. Conservation of resources: a new attempt at conceptualizing stress. Am Psychol 1989;44:513-24.

48 Hobfoll SE, Halbesleben J, Neveu J-P, et al. Conservation of resources in the organizational context: the reality of resources and their consequences. Ann Rev Organizat Psychol Organizat Behav 2018;5:103-28.

49 van Berkel J, Boot CRL, Proper KI, et al. Effectiveness of a worksite mindfulness-related multi-component health promotion intervention on work engagement and mental health: results of a randomized controlled trial. PLoS One 2014;9:e84118.

50 Moody K, Kramer D, Santizo RO. Helping the helpers: mindfulness training for burnout in pediatric oncology - a pilot program. $J$ Pediatr Oncol Nurs 2013;30:275-84.

51 Benn R, Akiva T, Arel S, et al. Mindfulness training effects for parents and educators of children with special needs. Dev Psychol 2012:48:1476-87.

52 Roeser RW, Skinner E, Beers J, et al. Mindfulness training and teachers' professional development: an emerging area of research and practice. Child Dev Perspect 2012;6:167-73.

53 Manotas MA. Brief mindfulness training to improve mental health with Colombian healthcare professionals. PHD thesis. San Francisco: California Institute of integral studies, 2013.

54 Aikens KA, Astin J, Pelletier KR, et al. Mindfulness goes to work: impact of an online workplace intervention. J Occup Environ Med 2014;56:721-31.

55 Bartlett L, Lovell P, Otahal P, et al. Acceptability, feasibility, and efficacy of a workplace mindfulness program for public sector employees: a pilot randomized controlled trial with informant reports. Mindfulness 2017;8:639-54.

56 Crain TL, Schonert-Reichl KA, Roeser RW. Cultivating teacher mindfulness: effects of a randomized controlled trial on work, home, and sleep outcomes. J Occup Health Psychol 2017;22:138-52.

57 Querstret D, Cropley M, Fife-Schaw C. Internet-Based instructorled mindfulness for work-related rumination, fatigue, and sleep: assessing facets of mindfulness as mechanisms of change. A randomized waitlist control trial. $J$ Occup Health Psychol 2017;22:153-69.
58 Islam G, Holm M, Karjalainen M. Sign of the times: workplace mindfulness as an empty signifier. Organization 2017;14:135050841774064.

59 Cohen-Katz J, Wiley SD, Capuano T, et al. The effects of mindfulness-based stress reduction on nurse stress and burnout: a quantitative and qualitative study. Holist Nurs Pract 2004;18:302-8.

60 Black PN, Carroll E. Nhs staff members' experiences of participating in an eight-week mindfulness programme: a service evaluation of a pilot programme. Clin Psychol Forum 2016;288:11-16.

61 Hugh-Jones S, Rose S, Koutsopoulou GZ, et al. How is stress reduced by a workplace mindfulness intervention? A qualitative study conceptualising experiences of change. Mindfulness 2018;9:474-87.

62 Davis BG. Preventing clergy burnout: assessing the value of a Mindfulness-Based intervention as part of a holistic clergy wellness program. PHD thesis. Philadelphia: Chestnut Hill College, 2011.

63 van Berkel J, Boot CRL, Proper KI, et al. Process evaluation of a workplace health promotion intervention aimed at improving work engagement and energy balance. J Occup Environ Med 2013;55:19-26.

64 Wolever RQ, Bobinet KJ, McCabe K, et al. Effective and viable Mind-body stress reduction in the workplace: a randomized controlled trial. J Occup Health Psychol 2012;17:246-58.

65 Ching $\mathrm{H}-\mathrm{H}$, Koo M, Tsai T-H, et al. Effects of a mindfulness meditation course on learning and cognitive performance among university students in Taiwan. Evid-Base Complement Alter Med 2015;2015:1-7

66 Allexandre D, Bernstein AM, Walker E, et al. A web-based mindfulness stress management program in a corporate call center. J Occup Environ Med 2016;58:254-64.

67 Koncz R, Wolfenden F, Hassed C. Mindfulness-based stress release program for university employees: a pilot, waitlist-controlled trial and implementation replication. J Occup Environ Med 2016:58:1021-7.

68 Arredondo M, Sabaté M, Valveny $\mathrm{N}$, et al. A mindfulness training program based on brief practices (M-PBI) to reduce stress in the workplace: a randomised controlled pilot study. Int J Occup Environ Health 2017;23:40-51.

69 Foureur M, Besley K, Burton G, et al. Enhancing the resilience of nurses and midwives: pilot of a mindfulness-based program for increased health, sense of coherence and decreased depression, anxiety and stress. Contemp Nurse 2013;45:114-25.

70 Duggan K, Julliard K. Implementation of a mindfulness moment initiative for healthcare professionals: perceptions of facilitators. EXPLORE 2018;14:44-58.

71 Lyddy CJ, Schachter Y, Reyer A, et al. Transfer of mindfulness training to the work setting: a qualitative study in a health care system. J Contin Educ Health Prof 2016;36:240-8.

72 den Heijer P, Koole W, Stettina CJ. Don't forget to breathe: a controlled trial of mindfulness practices in agile project teams. In: Baumeister H, Lichter H, Riebisch M, eds. Agile processes in software engineering and extreme programming. Cham: Springer, 2017: 103-18.

73 Banerjee M, Cavanagh K, Strauss C. A qualitative study with healthcare staff exploring the facilitators and barriers to engaging in a self-help mindfulness-based intervention. Mindfulness 2017;8:1653-64.

74 Cohen-Katz J, Wiley S, Capuano T, et al. The effects of mindfulness-based stress reduction on nurse stress and burnout: a qualitative and quantitative study, part III. Holist Nurs Pract 2005;19:78-86.

75 Darby M, Beavan V. Grist to the Mill: a qualitative investigation of mindfulness-integrated cognitive behaviour therapy for experienced health professionals. Aust Psychol 2017;52:491-502.

76 Irving JA, Park-Saltzman J, Fitzpatrick M, et al. Experiences of health care professionals enrolled in mindfulness-based medica practice: a grounded theory model. Mindfulness 2014;5:60-71.

77 Irving JA. Mindfulness-Based medical practice: a mixed-methods investigation of an adapted Mindfulness-Based stress reduction program for health care professionals. PHD thesis. Montreal, CA: McGill University, 2013.

78 Scott S. 8-week course in mindfulness - 2010. Evaluation report for health promotion NHS Fife 2010.

79 Bradbury $H$. Collaborative selflessness: toward an experiential understanding of the emergent "responsive self" in a caregiving context. J Appl Behav Sci 2014;50:55-79.

80 Beckman HB, Wendland M, Mooney C, et al. The impact of a program in mindful communication on primary care physicians. Acad Med 2012;87:815-9. 
81 Supiano KP, Overfelt VK. Honoring grief, honoring ourselves: mindfulness-based stress reduction education for grief group clinician-facilitators. Soc Work Ment Health 2018;16:62-73.

82 Ryff CD, Keyes CLM, Lee M. The structure of psychological wellbeing revisited. J Pers Soc Psychol 1995;69:719-27.

83 Ryff CD. Happiness is everything, or is it? Explorations on the meaning of psychological well-being. J Pers Soc Psychol 1989;57:1069-81.

84 Lazarus RS, Folkman S. Stress, appraisal, and coping. New York: Springer, 1984

85 Jamieson SD, Tuckey MR. Mindfulness interventions in the workplace: a critique of the current state of the literature. J Occup Health Psychol 2017;22:180-93.

86 Eby LT, Allen TD, Conley KM. Mindfulness-based training interventions for employees: a qualitative review of the literature. Human Res Manage Rev 2017

87 Gilmartin H, Goyal A, Hamati MC, et al. Brief mindfulness practices for healthcare providers - a systematic literature review. Am J Med 2017;130:1219.e1-17.

88 Hafenbrack AC. Mindfulness meditation as an on-the-spot workplace intervention. J Bus Res 2017;75:118-29.

89 Lyddy CJ, Good DJ. Being while doing: an inductive model of mindfulness at work. Front Psychol 2060;2016:7.

90 Boellinghaus I, Jones FW, Hutton J. The role of mindfulness and loving-kindness meditation in cultivating self-compassion and other-focused concern in health care professionals. Mindfulness 2014;5:129-38

91 DeMauro AA, Jennings PA, Cunningham T, et al. Mindfulness and caring in professional practice: an interdisciplinary review of qualitative research. Mindfulness 2019;10:1969-84.
92 Garland EL, Gaylord SA, Fredrickson BL. Positive reappraisal mediates the stress-reductive effects of mindfulness: an upward spiral process. Mindfulness 2011;2:59-67.

93 Garland EL, Hanley AW, Goldin PR, et al. Testing the mindfulnessto-meaning theory: evidence for mindful positive emotion regulation from a reanalysis of longitudinal data. PLoS One 2017;12:e0187727.

94 Hülsheger UR, Walkowiak A, Thommes MS. How can mindfulness be promoted? workload and recovery experiences as antecedents of daily fluctuations in mindfulness. J Occup Organ Psychol 2018;91:261-84.

95 TWH N, Feldman DC. Employee voice behavior: a meta-analytic test of the conservation of resources framework. J Organiz Behav 2012;33:216-34.

96 Schein EH, Bennis W. Personal and organizational change via group methods. New York: Wiley, 1965.

97 Kahn WA. Psychological conditions of personal engagement and disengagement at work. Academy Manag J 1990;33:692-724.

98 Sanner B, Bunderson JS. When feeling safe isn't enough. Organiz Psychol Rev 2015;5:224-43.

99 Agarwal P, Farndale E. High-Performance work systems and creativity implementation: the role of psychological capital and psychological safety. Human Res Manage J 2017;27:440-58.

100 Halbesleben JRB, Neveu J-P, Paustian-Underdahl SC, et al. Getting to the "COR". J Manage 2014;40:1334-64.

101 Hobföll S. Conservation of resources theory: its implication for stress, health, and resilience. In: Folkman S, ed. The Oxford Handbook of stress, health, and coping. New York: Oxford University Press, 2011: 127-47. 
Correction: Mindfulness-based programmes to reduce stress and enhance well-being at work: a realist review

Micklitz K, Wong G, Howick J. Mindfulness-based programmes to reduce stress and enhance well-being at work: a realist review. BMJ Open 2021;11:e043525. doi: 10.1136/ bmjopen-2020-043525

This article was previously published with an error. The author Geoffrey Wong should have been listed as Geoff Wong.

Open access This is an open access article distributed in accordance with the Creative Commons Attribution Non Commercial (CC BY-NC 4.0) license, which permits others to distribute, remix, adapt, build upon this work non-commercially, and license their derivative works on different terms, provided the original work is properly cited, appropriate credit is given, any changes made indicated, and the use is non-commercial. See: http://creativecommons.org/licenses/by-nc/4.0/.

(C) Author(s) (or their employer(s)) 2021. Re-use permitted under CC BY-NC. No commercial re-use. See rights and permissions. Published by BMJ.

BMJ Open 2021;11:e043525corr1. doi:10.1136/bmjopen-2020-043525corr1

(A) Check for updates 